\title{
Leaf-level responses to light in two co-occurring Quercus (Quercus ilex and Quercus suber): leaf structure, chemical composition and photosynthesis.
}

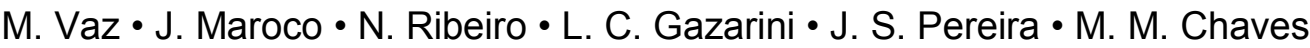 \\ Agroforest Syst (2011) 82:173-181
}

Abstract: We studied morphological, biochemical and physiological leaf acclimation to incident Photon Photosynthetic-Flux-Density (PPFD) in Quercus ilex (holm oak) and Quercus suber (cork oak) at Mediterranean evergreen oak woodlands of southern Portugal. Specific leaf area (SLA) decreased exponentially with increasing PPFD in both species. $Q$. ilex had lower SLA values than $Q$. suber. Leaf nitrogen, cellulose and lignin concentration (leaf area-based) scaled positively with PPFD. Maximum rate of carboxylation (Vcmax), capacity for maximum photosynthetic electron transport (Jmax), rate of triose-P utilization (VTPU) and the rate of nonphotorespiratory light respiration (Rd) were also positively correlated with PPFD in both Quercus species, when expressed in leaf area but not on leaf mass basis. $Q$ suber showed to have higher photosynthetic potential (Vcmax, Jmaxmm and VTPUm ) and a higher nitrogen efficient nitrogen use than $Q$. ilex. Leaf chlorophyll concentration increased with decreasing PPFD, improving apparent quantum use efficiency (U) in both Quercus species. We concluded that, in $Q$. ilex and $Q$. suber, leaf structural plasticity is a stronger determinant for leaf acclimation to PPFD than biochemical and physiological plasticity. 